\title{
SimUlación DEL YO Y MONÓlogo INTERIOR. EL RELATO DE SALINAS
}

\author{
Jerusalem GAGO \\ Universidad Carolina de Praga
}

\begin{abstract}
En): In contemporary storytelling, the narrative procedures evolve in their eagerness to penetrate the interior of consciousness and to develop techniques of simulation of the self as the inner monologue. When the narrated is situated on a plane other than space-time, and is built at the proper coordinates located in the inner zone of intimacy, we are faced with a reality governed by inner laws and marked by the time of mental processes. The writer tries to install us inside the mind of the character and refer to the reality directly internalized in the character. The term "stream of consciousness" refers to a type of narrative where the incessant passage of perceptions, ideas, feelings and the indefinable flow of inner experiences is simulated. Although born in the field of psychology, it was soon adopted by the critics of English language to define the voice used in works of the time, where the interior monologue and marked subjectivism opened a new path to the narrative. In the compilation of stories by Pedro Salinas, Vespers of the joy (1926), we find that interiority narrated as a flow of thoughts and impressions as they arise in the mind. In this way it places us at the crossroads of modernity.
\end{abstract}

Keywords (En): contemporary narrative ; inner monologue ; 20th century ; plot ; story ; short story ; Pedro Salinas

Palabras claves (Es): narrativa contemporánea ; monólogo interior ; siglo XX ; relato ; cuento literario ; Pedro Salinas

\section{Introducción}

En este breve artículo, se reflexiona sobre algunas técnicas de simulación de la interioridad en la narrativa contemporánea. Se comienza con unas consideraciones generales sobre la simulación en la narración y las instancias narrativas, luego se trata los géneros y técnicas de la interioridad con una breve exposición sobre del monólogo interior y sobre la llamada «corriente de conciencia». Se concluye con una visión panorámica del uso de tales métodos en Salinas.

\section{La simulación del yo: instancias narrativas}

La literatura, en cuanto ficción, es siempre simulación de un mundo posible (DOLEŽEL, 1998). En este marco teórico, la narración integra una serie de instancias ficticias que contribuyen al todo de la obra como una realidad simulada y reflejo de un autor. Cada elemento es igualmente pura representación. Y la simulación se da a todos los niveles de la narración.

Una de las instancias en la que la simulación se muestra de modo más diáfano es la voz narrativa y la perspectiva adoptada. El mundo de la novela es un «mundo lleno de voces, sin que una sola sea real» (TACCA, 1998:64). El autor inventa un narrador y se sitúa tras él, disimula su presencia tras la voz narrativa de un narrador omnisciente o equisciente (TACCA, 1989: 72). Se trata de un juego de 
informaciones en el que el autor las dosifica y presenta, bien en boca del narrador o en la de un personaje haciéndole intervenir en la narración, aunque el narrador suele llevar las riendas de la historia. Sin embargo, el grado de interioridad se mide por el punto de vista que se adopta, que, si es demasiado intenso, es capaz de transformarse en personaje llegando incluso a simular sus estados de conciencia.

Cuando lo narrado se sitúa en un plano distinto al espacio-temporal, y se constituye en unas coordenadas propias ubicadas en la zona interior de la intimidad, nos hallamos ante una realidad regida por leyes interiores y marcada por el tiempo de los procesos mentales. La naturaleza temporal de tal discurrir interior es de carácter subjetivo, es un tiempo psicológico ajeno al cronológico $u$ objetivo. Es intuitivo y en ese plano es donde realmente se hace posible una comprensión estética y ficcional.

Los mundos posibles plasmados en la narrativa de ficción se vierten hacia lo interior, en función de las coordenadas estéticas en las que se insertan. El romanticismo, el costumbrismo, el realismo o el modernismo, por nombrar algunas corrientes estéticas de las últimas centurias, se acercan a la realidad humana con pretensiones y resultados artísticos que difieren entre sí, no sólo por la temática u otros elementos narrativos, sino por la esencia misma de los mundos que pretenden simular. El nivel de interioridad, así como su simulación en cada caso, es distinto. La simulación de los mundos interiores aparece siempre mediatizada por unas técnicas narrativas que logran representar el fluir interior, algunas incluso de la conciencia misma en vivo. Mas no es una cuestión sólo de técnica, sino de materia de interés y orientación estética: interesan las realidades interiores. En opinión de Anderson Imbert, lo que hace que una técnica sea tradicional y otra innovadora no es el aparato gramatical, sino el nivel de subjetividad (ANDERSON IMBERT, 1992: 220).

La intencionalidad de expresar en la obra no tanto la realidad, sino (más bien) la imagen artística que el autor guarda de ella, se manifiesta tempranamente en los movimientos modernistas de finales de siglo XIX, e incluso en el romanticismo, se da una explosión de subjetividad, pero estos «reducían a un mínimo los elementos estrictamente estéticos y hacían consistir la obra casi por entero en la ficción de realidades humanas» (ORTEGA, 1984: 18).

La perspectiva subjetiva o interioridad del nuevo arte de la que habla Ortega es distinta. Ahora se pintan las ideas. Y en narrativa, se podría decir que se narran las historias desde su misma fuente interior. Se trata de un arte artístico (ORTEGA, 1984). Compara la visión del arte a la mirada a través de un vidrio. Los realismos y romanticismos de siglos anteriores se centraban en los objetos vistos a través del cristal. El arte nuevo se centra en el vidrio mismo y «no ve en ellas cosas humanas, sino sólo transparencias artísticas, puras virtualidades» (ORTEGA, 1984: 18). El modo de elaboración artístico, basado en la expresión de ideas en sus propias coordenadas será una constante en el arte y en la literatura contemporánea. El discurrir interior con sus emanaciones conceptuales, así como los productos de la imaginación desprovistos de la realidad que los evoca, son la clave para entender el juego de voces a la que se somete la narrativa contemporánea. El extremo al que se llega en la vanguardia de los años veinte y posteriormente en narrativas posmodernas, nos sitúa en simulaciones totales que se mueven incluso 
en parámetros de caotismo y de fragmentación en el mundo de lo inconsciente. Mas ahora nos ocupa la indagación de la subjetividad en la narrativa contemporánea y tan sólo nos detendremos lo justo en la cuestión de la expresión narrativa de la inconsciente.

\section{Géneros y técnicas de la interioridad}

Los mundos interiores fueron expresados por escrito a lo largo de la historia, a través de géneros como la poesía lírica, el diario íntimo, el relato autobiográfico, las formas epistolares, etc., y de modo parcial en fragmentos dentro de obras no específicamente interiores por medio de técnicas narrativas como el soliloquio y el monólogo.

En el siglo XIX, con el cultivo de una narrativa realista, se desata un creciente interés estético por describir y mostrar la complejidad de los personajes. Este afán por ahondar en los conflictos psicológicos llevará a que se extienda el uso de procedimientos para referir los fenómenos psíquicos. Los recursos utilizados para narrar estos fenómenos fueron varios y la crítica los ha categorizado de manera dispar. El crítico Anderson Imbert, en un intento de describir las técnicas propias del XIX, distingue: el informe del narrador psicológico, la introspección y el análisis interior indirecto (ANDERSON IMBERT, 1992: 217).

El informe del narrador psicológico ofrece los detalles necesarios para que el lector entienda al personaje. Se trata de un narrador omnisciente o cuasi omnisciente que, cuando emplea el discurso indirecto libre, pretende un nivel de profundidad mayor al mostrar al personaje en su vertiente no sólo de acción sino de intención. La introspección, que también es la técnica de la autobiografía, usa de la primera persona gramatical. Recurre con frecuencia al monólogo o soliloquio, que comunica el producto final una mayor interioridad elaborada lingǘsticamente. Se trata de incisos de soliloquio interior para sacar a la luz pensamientos puntuales de los personajes. Y por último, el análisis interior indirecto presenta los pensamientos no formulados explícitamente del personaje. Es una técnica a caballo entre lo tradicional y lo innovador, pues con ella el escritor ya penetra en zonas interiores del pensar del personaje. El narrador en cierto modo se identifica con el personaje. El narrador omnisciente sugiere lo que el personaje diría si su interioridad se expresara. Utiliza el pronombre de la tercera persona. Es un puente hacia las técnicas innovadoras, pero aún permanece totalmente en la zona clásica de la verbalización lógica.

Este tipo de técnicas que narran con más incisividad la psicología de los personajes y los conflictos de los sujetos, se puede observar ya en narraciones tempranas como Veinte años después (1845) de Alejandro Dumas padre, Cosmópolis (1893) de Paull Bourget, La sumisa (1876) de Dostoievski, Cuatro días (1877) de Vsevolod Garchine, Relatos de Sebastopol (1855) de Tolstoi, por citar algunos autores y obras consideradas como precedentes del llamado monólogo interior. En el ámbito de la literatura española del siglo XIX, es Galdós quien comienza a hacer uso de este procedimiento narrativo, que en palabras de Clarín, aparece descrito como la sustitución de «las reflexiones que el autor suele hacer por su cuenta respecto de la situación de un personaje, con las reflexiones 
del personaje mismo, empleando su propio estilo, pero no a guisa de monólogo, sino como si el autor estuviera dentro del personaje mismo y la novela se fuera haciendo dentro del cerebro de éste» (ALAS, 1991: 90).

En la época contemporánea, la narrativa se ha orientado hacia el uso de procedimientos que no sólo pretenden mostrar la psicología, sino que, en su afán de profundización, llegan a hacer transparentes el pensar de los personajes (COHN, 1978). Destaca el monólogo interior, técnica considerada como más ad hoc a la expresión de la interioridad, pues con ella la narrativa evoluciona en su itinerario hacia el interior de la conciencia. Anderson Imbert (1979 : 217) lo define como «una convención que, con palabras astutamente elegidas, finge el tácito discurrir de un personaje».

El monólogo interior es un procedimiento narrativo mediante el cual el escritor nos instala en la mente del personaje y refiere la realidad interiorizada. Se produce un cambio de perspectiva que se traslada a la interior del personaje y desde esa zona del espíritu se teje la narración. Con las técnicas tradicionales era posible observar la intimidad del personaje moldeada por el lenguaje, o, si se quería exponer niveles preverbales de la intimidad, lo verbalizaban en modos coherentes.

En general, determina una cierta autonomía respecto a la voz del autor. El narrador incluso disimula su papel de expositor y en ocasiones, se esconde en la mente del personaje desde donde nos relata lo que piensa en su mismo fluir. El autor, distanciado del narrador, se distancia aún más del personaje que permanece sólo en su inmanencia ante el lector, llegando a alcanzar la simulación altas cotas de verosimilitud. En el siglo XX algunos innovadores pretenden llegar incluso a aquella intimidad que el personaje mismo todavía no ha llegado a transformar en lenguaje y ni siquiera es posible hacerlo. Entonces, el narrador recurriendo a procedimientos literarios, consigue simular un discurso incoherente e ilógico.

Es una de las técnicas que mejor estandariza el modo de expresar los procesos interiores. Este método de orden subjetivo se relaciona con la interiorización propia de la narración contemporánea. El tiempo objetivo discurre progresivamente, pero no sucede lo mismo respecto a la percepción subjetiva de cada individuo. El autor concede al tiempo del relato un orden subjetivo, un orden que estéticamente resulta ser la expresión de sus leyes interiores, diversa a la cronología lógica (REY BRIONES, 2008: 72).

\section{El monólogo interior y la llamada «corriente de conciencia»}

A finales del XIX aparece un género narrativo que se ha denominado «corriente de conciencia» - «stream of consciousness»- y es una representación literaria de la durée Bergsoniana. La expresión «stream of consciousness» fue acuñada por William James, en Principles of Psychology (1890). Se trata de un término psicológico que traza una analogía entre el fluir del mundo interior del hombre y el correr de las aguas de un río. La corriente de conciencia expresa el incesante transcurso de percepciones, ideas, sentimientos, recuerdos y el caudal indefinible de experiencias interiores que se desliza entre lo racional y lo irracional, lo emotivo y lo inteligente, el olvido y la memoria. La expresión nacida en el ámbito de la psicología pronto fue adoptada por la crítica de lengua inglesa 
para definir la voz usada en obras de la época, donde el monólogo interior y el marcado subjetivismo abrían un nuevo camino a la narrativa. Entre estos autores se encuentra James Joyce, Virginia Woolf, William Faulkner, Dorothy Richardson, Henry James - hermano del inventor del nuevo cuño - y otros.

Llegados a este punto, es necesario distinguir el monólogo interior de la llamada «corriente de conciencia» (BURUNAT, 1980: 16). La novela de «corriente de conciencia» se considera un tipo de novela, mientras que el monólogo interior es una técnica narrativa propia, aunque no exclusiva de este género novelesco. Este género hace uso también de otros procedimientos como son el análisis interno y la impresión sensorial (Burunat, 1980: 17). En el análisis interno, el autor presenta un resumen de las impresiones del personaje. La impresión sensorial pretende recoger las sensaciones más puras de los personajes. El monólogo interior es aún más amplio, pues cubre todos los niveles de la interioridad y se sitúa en el nivel de las voces de la narración.

Una cuestión planteada sobre el género del «stream of consciousness» y la técnica del monólogo interior es la posibilidad o imposibilidad de reflejar lingüísticamente los mundos interiores. La novedad que con frecuencia la crítica atribuye igualmente a la narrativa contemporánea es un tipo de monólogo interior que no se organiza sobre una base lingüística o estilística, sino sobre el mismo fluir psíquico del personaje. «La prosa de la narración de pronto entra en laberintos sintácticos que remedan laberintos psicológicos» (ANDERSON IMBERT, 1992: 217).

Ciertamente el discurso de la conciencia no siempre está necesariamente atado a la lógica verbal, y por este motivo con frecuencia se le confunde con el caos o con lo inconsciente no reflexionado. Algunos consideran que el monólogo es un recurso estético, pues la interioridad de la conciencia es realmente inaprensible e incomunicable como discurso. Se trata de una convención que hace suponer que lo que expresa el monólogo interior es el pensar real del personaje, ya sea en primera o en tercera persona. Pero esto es una ficción más, una simulación, pues la interioridad en su parte pre-racional o previa a lo reflexivo es de naturaleza no verbal y por tanto incomunicable en ese estado. Mas en el momento en que se transforma en discurso y por tanto reflexivo en cuanto se verbaliza, deja de ser aquel mundo espontáneo, irracional aún y caótico para convertirse en pensamiento racional.

Anderson Imbert opina igualmente la imposibilidad de manifestar la subjetividad completa en formas verbales, pues la corriente de conciencia, en cuanto referida al conjunto de experiencias como son las sensaciones, emociones, imágenes, recuerdos, deseos, razonamientos, es preverbal y, según él, «es imposible presentar la incoherencia no hablada con un habla coherente» (ANDERSON IMBERT, 1992: 211). Con estas palabras sintetiza la dificultad de mostrar de modo pleno la subjetividad. El narrador tan sólo puede expresar en un discurso lingüístico el mundo interior reflexionado, pues no es posible expresar con palabras una realidad que en su inicial emersión de captación sensitiva es anterior a la verbalización. La interioridad en este sentido es inaprehensible y los escritores sólo pueden simular aprehenderla. 
En este razonamiento, podemos dar un paso más allá. Como no es posible que se exprese verbalmente de modo pleno una subjetividad que sólo se conoce de modo intuitivo y singular, el único modo de simular la misma corriente interior es el lenguaje metafórico propio de la novela lírica (GuLlón, 1984). El fluir de la subjetividad meramente sensitiva es irracional, ilógico, amorfo, preverbal y se resiste al lenguaje discursivo y por este motivo, el narrador ha de introducirse en el lenguaje simbólico del habla, dejando de lado en ocasiones el armazón más lógico y discursivo del lenguaje (ANDERSON IMBERT, 1992: 212). Más cuando el autor decide narrar el pensar mismo, y no sólo el imaginar u otras operaciones de carácter interior que no está marcado por la reflexión, entonces aquello que escribe sí tiene una lógica verbal, pues el hombre más allá, o más bien por encima, de captar la realidad, imaginarla o recordarla en imágenes sensibles, reflexiona y concibe sus pensamientos a través del lenguaje. Por tanto, podemos afirmar que en cierto modo la verbalización de la interioridad es posible en ciertas zonas de la conciencia reservadas al pensamiento.

No obstante, hemos de señalar que el monólogo interior directo no es la escritura automática desasida de significación lógica, que corre impulsada por imágenes en libertad, ni es la introspección posmoderna donde el personaje no es plenamente consciente de sí mismo ni toma posesión de su intimidad con un discurso inteligente. Esto constituiría más bien un fingimiento de monólogo interior directo, balbuceante, caótico, que el lector acepta como simulación, a la vez que él también hace creer que está en contacto inmediato con lo más íntimo del personaje (ANDERSON IMBERT, 1992: 224). Propiamente encontramos este tipo de escritura en las llamadas vanguardias de los años veinte con corrientes como el surrealismo, el dadaísmo y otros -ismos que conceden a la inconsciencia un papel rector en la creación artística.

El monólogo interior en cuanto técnica de simulación del yo del personaje distinto al yo ficticio del narrador y aún más alejado del yo del autor, es un método que alcanzará su apogeo entrado el siglo XX. Esta intensa simulación de la interioridad la encontramos en los relatos de Salinas que constituye un precedente hispano en la narrativa de la conciencia.

\section{La interioridad en Pedro Salinas}

Víspera del gozo (1926) fue una colección de narraciones breves ${ }^{1}$, las únicas de Pedro Salinas, conocido más bien por su labor de poeta. Justamente, fragmentos de este libro inauguraron la serie de ficción vanguardista Nova Novorum de la editorial Revista de Occidente a principios de los años veinte del siglo pasado. No obstante, Víspera del gozo no es una obra pura del espíritu de los llamados -ismos en cuanto que carece, entre otras cosas, de la subversión linguiística de la mayoría de los relatos de la vanguardia hispana.

\footnotetext{
${ }^{1}$ La obra se compone de siete relatos breves: «Mundo cerrado» de siete páginas, «Entrada en Sevilla» de seis, «Cita de los tres» de nueve, «Delirio del chopo y el ciprés» de tres páginas y media, «Aurora de verdad» de cinco y media, «Volverla a ver» de seis, «Livia Schubert, incompleta» de doce páginas.
} 
Salinas es un autor lírico que deja en su obra tanto poética como narrativa la fuerza de su expresión interior por medio de recursos propios de la novela lírica y a través del juego de las voces interiores. Los relatos de Salinas simulan un alto nivel de subjetividad que viene dado no sólo por el tema, de índole tan íntima como los distintos modos de espera de un amante a su amada, sino porque reproduce el reducto interior del personaje en una combinación de técnicas introspectivas, así como a través del uso de los distintos tipos de monólogo. Son relatos que «tienen como única apoyadura externa, como escenario, unas breves referencias contadas con alta densidad poética» (MAINER, 2000: 155).

De los siete relatos contenidos en Víspera del gozo, dos están escritos en primera persona («Volverla a ver y Livia», «Schubert incompleta»), cuatro en tercera persona con narrador cuasi omnisciente porque parece saber lo que el protagonista sabe y nos narra los hechos según el mismo los percibe («Mundo cerrado», «Entrada en Sevilla», «Cita de los tres», «Aurora de verdad»). Uno de los siete relatos («Delirio del chopo y el ciprés») es en forma de diálogo y por su falta de homogeneidad con el resto, lo dejaremos de lado en este artículo.

En todos, observamos diversas técnicas de interiorización, y asimismo es posible encuadrarlo en el género de la «corriente de conciencia». A lo largo de la obra, se reflejan el flujo de pensamientos, impresiones, ideas, recuerdos, sensaciones, reflexiones surgidas en la mente, aunque ya transformadas en palabras mediante un proceso de verbalización creativa. La simulación de que leemos en directo en la mente del personaje nos ubica en una realidad psíquica de intenso intimismo dado tanto por el uso de las voces como por el estilo lírico de la obra.

La introspección, llamada también técnica de la autobiografía, ya en pleno vigor en la novela realista del XIX, se halla en todos los relatos en proporciones distintas. Inicialmente «Volverla a ver» $\mathrm{y}$ «Livia Schubert, incompleta» se puedan afrontar como introspección. Sin embargo, el autor va más allá de los rasgos peculiares del mismo análisis introspectivo superando las coordenadas de causalidad, simplicidad y claridad que suele caracterizar a esta técnica. Ambos están escritos en primera persona, con monólogo o soliloquios esporádicos. El narrador es el propio protagonista y no encontramos una mínima interferencia del autor. Se trata de un monólogo que, en palabras de Imbert

\footnotetext{
se caracteriza, no tanto por ser interior, sino por hacernos creer que se ha emancipado de la autoridad del narrador para saltar de golpe a la narración y ocupar el primer plano. La ilusión de ser un discurso inmediato se debe a que no notamos el entrometimiento del narrador.(ANDERSON IMBERT, 1992: 223)
}

En «Volverla a ver» (SALINAS, 1974: 71-82) la historia se inicia en primera persona más bien a modo general de autobiografía narrando la estancia del protagonista en un hotel a la espera de una mujer a la que amó en otro momento. La descripción se desarrolla en unas coordenadas metafóricas dónde el narrador trae a colación reflexiones personales: sus impresiones de la vista desde el balcón, lo que piensa a raíz del paisaje a modo casi de ensayo. El tono es intensamente lírico. Se trata de una inmersión en la conciencia que reproduce fielmente su devenir en lo que tienen de espontáneo, de extremadamente poético e incluso 
caótico. Su verdadera realidad está dada en el plano de la expresión mediante la introducción de un discurso intimista resumido en una de las reflexiones sobre lo que observa alrededor.

Mas dónde el monólogo interior directo hace su aparición más cabal es en «Livia Schubert, incompleta» (SALINAS, 1974: 83-105). El narrador es el mismo protagonista en su reflexionar sobre la mujer que ama en sus últimos momentos con ella al amanecer. Ella duerme y él reflexiona sobre su feminidad, sobre el papel de aquella mujer en su felicidad, una felicidad que está a punto de acabar porque ella se va en breve. Esta primera parte ocupa doce de las diecinueve páginas del relato, y nos muestra el peso que juega en el relato la disquisición del personaje. La segunda parte es la partida de Livia desde la estación de tren. Se detiene en sus elucubraciones sobre los incidentes de la despedida. El mundo interior del protagonista prevalece sobre los hechos en sí que no son sino ocasión de desplegar la intimidad de modo metafórico, incluso con visos filosóficos. No interesa, pues, sino la conciencia del personaje sobre la realidad externa, quedando ésta reducida a un mero escenario minimalista.

Durante la partida de la mujer que se irá en tren de la estación, recrea en metáforas los distintos elementos de la despedida. Así, por ejemplo, cree que su suerte está escrita en el listado de horarios de trenes por aparecer la hora de partida de Livia:

\footnotetext{
Mi infelicidad está escrita, no en el libro enorme y tan difícil de consultar del destino, sino en una guía de ferrocarriles, en el renglón dice: Lucéntum: llegada, una y treinta y dos: salida, una y treinta y cinco. Y no lleva mi desdicha uno de esos nombres pomposos definitivos que la suelen poner las gentes - dolor, desesperación, desengaño, muerte -; se llama, sencillamente, expreso 22, París-Praga; tono afilado y de metal, como una saeta disparada eléctricamente por el arco tendido de la Gare du Nord, que irá a caer allá en Praga, Walisova, sin haber encontrado otro obstáculo en su camino que este blando corazón inesperado, el mío que se puso en medio y será atravesado limpiamente, sin sangre, esta noche a la una y treinta y cinco. (SALINAS, 1974: 87)
}

Sucede en algunos relatos, como en este, que el protagonista considera que sus pensamientos poseen una fuerza de realidad tal, que cree haber construido una imagen ideal paralela a la mujer de verdad a fuerza de recrearla mentalmente. Por eso, exclama al final de la primera parte: «Me miro vivo, despierto, en la patética vigilia de la despedida, en su faz dormida. Estoy en ella por última vez. Porque en cuanto Livia despierte empezará, lenta y minuciosa, mi destrucción, la ruina de mi efímera obra» (SALINAS, 1974: 90). Como consecuencia de tanto pensar en los encantos de la mujer, le acaba «haciendo un alma» idealizada en su mente. Esa concepción llega a cobrar una fuerza ontológica en su pensamiento tan real como la Livia de carne y hueso. Esto mismo sucede en «Aurora de verdad», donde igualmente de tanto imaginarla, acaba inventando una persona distinta, una Aurora imaginaria que contrasta con la que luego aparece en la cita, que es la Aurora de verdad, de ahí el título. Así, al final después de haber estado «inventándola» a base de pensarla, ha de exclamar cuando aparece la chica real:

La creación fidelísima, de la mañana y el pensamiento, la figura inventada y esperada se venía abajo de un golpe, porque Jorge la había labrado con lo conocido, con los datos de ayer, con el pasado. Y lo que tenía delante, intacta y novísima, en la virginal pureza del paraíso, 
tendiéndole la mano, contra costumbre sin guante, era la vida de hoy, era Aurora de verdad. (SALINAS, 1974: 69)

Pasando a comentar el monólogo interior indirecto de narrador omnisciente, hemos de mencionar cuatro relatos: «Mundo cerrado», «Entrada en Sevilla», «Cita de los tres»y «Aurora de verdad».

En «Mundo cerrado» (SALINAS, 1974: 9-22) Salinas combina las voces: de narrador en tercera persona cuasi omnisciente - porque no lo sabe todo-, pasa a la voz interior del personaje a modo bien de soliloquio bien de monólogo. El tema es nuevamente un encuentro con una mujer. Un hombre relata un viaje en tren hacia la ciudad donde ella vive. No cuenta acción alguna, sino lo que piensa a raíz de lo que observa. Las circunstancias del viaje van saliendo a la luz al hilo del vagar interior sobre lo circundante.

Miró el nombre de la ciudad adonde se dirigía: Icosia. Capital menor de Europa, de encanto elegante, tímido y reposado, como el de esa hermana pequeña de una beldad famosa, menos guapa, menos inteligente, pero que, sin embargo, tiene siempre un semblante sonriente y feliz, una expresión secundaria y muy suya. Junto a Icosia había escrito y borrado, cual una esperanza que se abandona, y luego, con letra muy reciente: Lady Gurney. Sonrió. Porque, en realidad, a esta amiga, Lady Gurney, que le allanaba el acceso a Icosia, no la conocía. (SALINAS, 1974: 17)

Va a ver a una antigua amiga, que ahora casada, vive en Icosia, pero hace muchos años que no sabe de ella y toma del pasado imágenes que la evocan. Aunque pretende simular el discurrir mismo del protagonista, el autor se deja ver a veces de modo obvio:

«La pregunta del empleado, brusca y disyuntiva, como unas tijeras, cortó el monólogo interior, le dejó trunco, en dos pedazos el mejor y más sabroso, el que quedaba dentro, el del recuerdo inexpresado.» (SALINAS, 1974: 19)

Otras, realmente desaparece simulando presentar el fluir mental en directo:

¿Cómo sería Lady Gurney? Ojos pardos, ¿de qué color ahora? Andar suyo, breve, enérgico, y quizá hoy conquistado, cual por un ritmo misterioso y lejano. (SALINAS, 1974: 18)

En «Cita de los tres» (SALINAS, 1974: 35-50) el escenario varía. Ahora es una cita y su previo desarrollo antes de verla, lo que un narrador aparentemente extradiegético y omnisciente nos presenta. Se trata de una omnisciencia con cierta peculiaridad, porque en su lírico reflexionar, no se sabe del todo si quien piensa es el narrador o el protagonista. A pesar de narrarse en tercera persona, podrían ser pensamientos del personaje sobre lo que vive o del narrador que los pone en boca del protagonista. La cita esta vez será en una iglesia del pueblo. La chica llegará, como en casi todos los relatos, al final. Lo que sabemos de ella es lo que nos presenta la narración como un puro pensamiento idealizado de la mujer que llegará. A la vez el narrador hace una espléndida reflexión sobre el paso del tiempo y los ritmos en la pequeña localidad donde vive, que parece tener otro ritmo. 
Las horas tenían exquisitas dilataciones imprevistas, llegaban antes de llegar igual que llega la persona que esperamos mucho antes de que esté aquí, sólo con su silueta adelantándose, resbalando toda hacia nosotros por la pulida superficie de este puente que echamos sobre la distancia, a medias, de una sonrisa suya y otra nuestra, separados y unidas. (SALINAS, 1974: 38)

En el siguiente relato «Aurora de verdad» (SALINAS, 1974: 59-70) la cita es en un museo. Relata la preparación del protagonista desde que se levanta hasta que llega al museo y se encuentra con la chica. El esquema es el mismo que los anteriores: omnisciencia, tercera persona, focalización extradiegética. El anhelo de la expectativa nuevamente:

Aurora y Jorge habían convenido en citarse cada día en una sala distinta, por orden estrictamente cronológico, lo cual, si tenía el inconveniente de parecer a primera vista escolarmente pedantesco, ofrecía a Aurora un fondo cambiante y siempre bellísimo." (SALINAS, 1974: 67)

En ocasiones, cambia el registro expresivo dando a las digresiones y a la arbitrariedad discursiva, un efecto estético de intimismo:

Desdeñoso de los cuadros en torno, se volvió hacia su imaginación, donde la vería, a ella casi completa, tocada, vestida, calzada con aquellas impalpables prendas espigadas en el camino y el recuerdo. Sí, así era: iba a llegar, en realidad, pero estaba ahora tan familiar, allí dentro tan parecida, hecha casi por él, que su aparición no le sorprendería sino como la última inspiración felicísima que da remato a un poema trabajado mucho tiempo y que ya se sabe casi de memoria. (SALINAS, 1974: 68)

Por último, «Entrada en Sevilla» rompe el esquema temático de la cita. Esta vez, lo que invade los pensamientos del protagonista no son los anhelos por la mujer amada, sino un trayecto en coche por la ciudad de Sevilla. El protagonista se limita a describir las distintas percepciones visuales y auditivas de la ciudad conforme va pasando por sus calles. El relato resulta ser un collage de impresiones sensibles y, en definitiva, se trata de un proceso cognoscitivo donde la acción queda absolutamente desplazada, pues no interesa sino como ocasión o excusa que posibilita el análisis de una realidad concreta, la ciudad de Sevilla, desde una perspectiva epistemológica. Algunos de los pasajes presentan metáforas o figuras que muestran una visión poética o artística de la vida a la que la lógica común no llega. «Entrada en Sevilla» con su percepción fragmentaria de la ciudad parece ser una intencionada reflexión sobre el conocimiento humano y su modo de captar la realidad física. Este relato muestra un intento de recrear la pura percepción sensitiva del mundo:

Todo lo que aprehendían los ojos eran fragmento, cortes y paños de muros, rosa, verde, azul, y de trecho en trecho, como un punto redondo y negro que intenta dar apariencias de orden a una prosa en tumulto, un portal en el que se hundía la mirada siempre demasiado tarde, ... (SALINAS, 1974: 29) 


\section{Conclusión}

Acabamos con una consideración de cierre. En los relatos de Salinas, se aprecia aquella noción de interioridad que fue uno de los rasgos más destacados de la renovación narrativa del siglo XX. La vía más adecuada de formular los estados de intuición de la realidad es probablemente desde dentro de la misma percepción. Y Salinas logró en su narrativa alcanzar de modo magistral mostrar una literatura que más allá de describir, indaga en la dimensión epistemológica de la vida. Víspera del gozo (1926), se puede considerar un referente en el ámbito hispano del monólogo interior y «la corriente de conciencia», y un símbolo de la contemporaneidad naciente.

\section{BIBLIOGRAFÍA}

ALAS Leopoldo (Clarín) (1991), Galdós, novelista, Barcelona, PPU.

ANDERSON IMBERT Enrique (1992), Teoría y técnica del cuento, Barcelona, Ariel. AZNAR ANGLÉS Eduardo (1996), El monólogo interior. Un análisis textual y pragmático del lenguaje interior en la literatura, Barcelona, EUB.

BURUNAT Silvia (1980), El monólogo interior como forma narrativa en la novela española, Madrid, José Porrúa Turanzas Ediciones.

CoHN Dorrit (1978), Transparent Minds, Princeton, Nueva Jersey, Pricenton University Press.

DOLEŽEL Lubomír (1998), Heterocosmica. Fikce a možné světy, Baltimore, The Johns Hopkins University Press.

GuLlón Germán (1976), El narrador en la novela del siglo XIX, Madrid, Taurus.

Gullón Ricardo (1984), La novela lírica, Madrid, Cátedra.

MAINER José Carlos (2000), La escritura desatada, Madrid, Temas de hoy.

TACCA Oscar (1973), Las voces de la novela, Madrid, Gredos.

ORTEGA Y GASSET José (1984), La deshumanización del arte, Madrid, Alianza Editorial.

REY BRIONES Antonio del (ed.), El cuento literario, Madrid, Akal.

SALINAS Pedro (1976), Narrativa completa, Barral Editores, Barcelona. 